care under these circumstances. The use of a precurved Silastic nasopharyngeal airway to facilitate insertion of the NG tube, as described by Bouzarth, ${ }^{12}$ may help prevent intracranial complications of this procedure.

1 Dyer I, Ashton WB. How to pass a nasogastric tube. $\mathrm{Br} \mathrm{J}$ Hosp Med 1991;45:45-6.

2 Azumi N, Matsuno T, Tateyama M, Inoue K. So called nasal glioma. Acta Pathol Jpn 1994;34:215-20.

3 Braun M, Boman F, Hascoet JM. Brain tissue heterotropia in the nasopharynx. Contribution of MRI to assessment of extension. J Neuroradiol 1992;19:68-74.

4 Glasser SA, Garfinkle W, Scanlon M. Intracranial complication during insertion of a nasogastric tube. Am J Neuroradiol 1990;11:1170

5 van den Anker JN, Baerts W, Quak JME, Robben SGF,
Meradji N. Iatrogenic perforation of the lamina cribrosa by nasogastric tube in an infant. Pediatr Radiol 1992;22:545-6.

6 Committee on Trauma American College of Surgeons. Advanced Trauma Life Support. Core course, 1993.

7 Sacks AD. Intracranial placement of a nasogastric tube after complex craniofacial trauma. Ear Nose Throat J 1993;72: 800-2.

8 Katz MI, Faibel M. Inadvertent intracranial placement of a nasogastric tube?. Am J Roentgenol 1994;163:222.

9 Vincent MT, Goldman BS. Anaerobic lung infections. Am Fam Physician 1994;49:1815-20.

10 Schwartz CI, Heyman AS, Rao AC. Prophylactic nasogastric tube decompression: is its use justified? South Med J tric tube decomp

11 Cheatham ML, Chapman WC, Key SP, Sawyer SJL. A meta-analysis of selective versus routine nasogastric decompression after elective laparotomy. Ann Surg 1995; 221:469-76.

12 Bouzarth W. Intracranial nasogastric tube insertion. J Trauma 1978;18:818-9.

\title{
Traumatic asphyxia in children
}

\author{
Gregor Campbell-Hewson, Conor V Egleston, Andrew R Cope
}

\begin{abstract}
Two cases of traumatic asphyxia in young children are reported. The first was a 2 year old child run over at low speed by the front wheels of a delivery van. He made an uncomplicated recovery. The second child was pinned to the floor by an empty chest of drawers in an unwitnessed accident. He was discovered in cardiac arrest and resuscitation was unsuccessful. The outcome following traumatic asphyxia is a product of duration of compression and the weight involved. Considerable weight can be tolerated for a short period, whereas a comparatively modest weight applied for a longer period may result in death.

(F Accid Emerg Med 1997;14:47-49)
\end{abstract}

Keywords; children; crush asphyxia; traumatic asphyxia

\section{Accident and Emergency Department, Addenbrooke's Hospital, Cambridge G Campbell-Hewson C V Egleston}

Accident and Emergency, Peterborough District Hospital, Peterborough A R Cope

Correspondence to: Dr Gregor

Campbell-Hewson, Accident and Emergency Department, Addenbrooke's Hospital, Hills Road, Cambridge CB2 2QQ.

Accepted for publication 4 September 1996.
The syndrome of traumatic asphyxia has been reported regularly in medical publications since its initial description by D'Angers Ollivier following his observations on the cadavers of people trampled upon during crowd disturbances in Paris on Bastille day 1837. ${ }^{1}$ It has been defined as cervico-facial cyanosis, subconjunctival haemorrhage, and cutaneous petechial haemorrhages following thoraco-abdominal compression. ${ }^{2}$

It was recently brought to prominence by the Hillsborough Stadium disaster where the victims bore some of the stigmata of traumatic asphyxia, although there were marked differences in presentation and outcome. ${ }^{34}$

The purpose of this paper is to report two cases of traumatic asphyxia in young children which show important and contrasting features of the pathophysiology of this condition, and to review the relevant published reports.
Case 1

The patient, a healthy 2 year old boy, chased a ball onto a road. He fell and his torso was run over by the front wheel of a delivery van (Ford Transit, unladen weight $1533-2075 \mathrm{~kg}$ ). The van had been driving slowly and stopped before the back wheels had reached the child. $\mathrm{He}$ did not lose consciousness and remained motionless under the van on the instructions of his parents.

On arrival in accident and emergency (A\&E) he was alert but jittery. His blood pressure was $105 / 55$, pulse 115 , respiratory rate 18 , and he was well perfused. He complained of abdominal pain which was poorly localised. His facial appearance was striking, with cervicofacial cyanosis and swelling, widespread petechiae, and bilateral subconjunctival haemorrhages (figure). There were no marks of compression on the torso. On fundoscopy there were bilateral retinal haemorrhages and exudates. Otherwise neurological examination was normal. There were no fractures or other abnormalities on radiographs of the skull, cervical spine, or chest. A plain abdominal radiograph showed acute gastric dilatation. He was initially treated with oxygen, intravenous fluids, urinary catheterisation, and insertion of a nasogastric tube to decompress the stomach. Arterial blood gases, haematology, and biochemistry profiles were all normal. A further chest radiograph 18 hours after the accident was also normal. An ultrasound of the abdomen failed to show any abdominal injury. Clinically he made good progress, although his dramatic facial appearance persisted. He was discharged 8 days later, by which time his appearance had almost returned to normal with only the resolving subconjunctival haemorrhages remaining. The main reason for his prolonged inpatient stay was the development of a swinging pyrexia on day 4 caused by an urinary tract infection, presumably secondary to catheteri- 

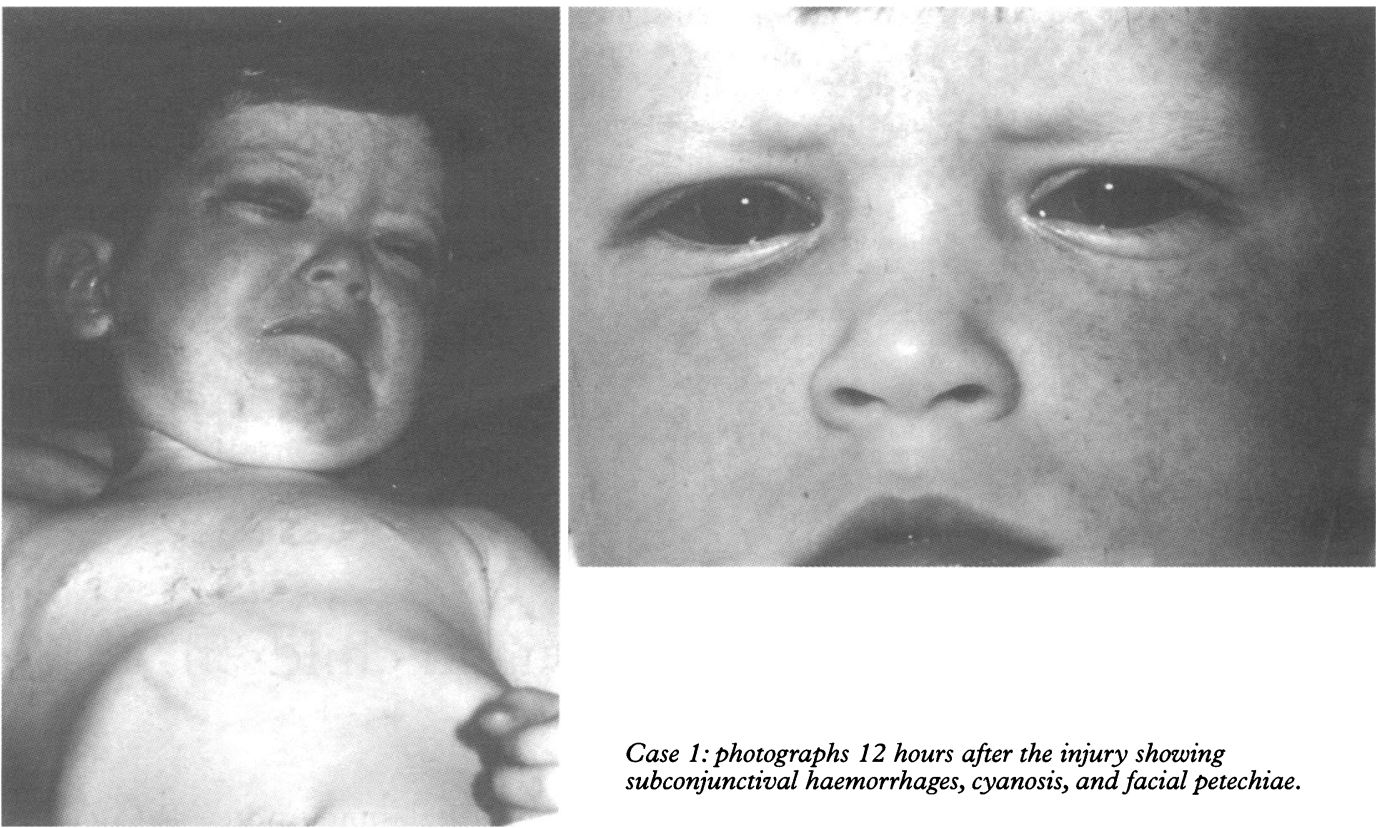

Case 1: photographs 12 hours after the injury showing subconjunctival haemorrhages, cyanosis, and facial petechiae. sation. At the time of his review one month later examination was entirely normal.

Nine years after the accident he is healthy without any cognitive impairment or focal neurological deficit.

\section{Case 2}

The patient, an 18 month old boy, was one of twins and had no significant past medical history. His parents were profoundly deaf but had equipped their house with an intercom system using a sound activated LED (light emitting diode) display.

He had been put to bed in the late afternoon as usual and was found approximately one hour later trapped under an overturned empty chest of drawers. It was not possible to ascertain the duration of the entrapment because the parents had not heard the chest being overturned. The parents began mouth to mouth resuscitation when they found the child unresponsive and apnoeic. On arrival of the ambulance crew, cardiac arrest was confirmed. $\mathrm{He}$ was intubated and ventilated with $100 \%$ oxygen and chest compressions were continued. On arrival in $\mathrm{A} \& \mathrm{E}$ he was given boluses of adrenaline, atropine, and sodium bicarbonate. $\mathrm{He}$ remained asystolic throughout. Arterial blood gases were analysed and showed a $\mathrm{pH}$ of $6.367, \mathrm{PCO}_{2} 17.94 \mathrm{kPa}, \mathrm{Po}_{2} 5.7 \mathrm{kPa}$, and a base excess of -39.1 . He was not hypothermic. $\mathrm{He}$ remained asystolic and after 25 minutes of full resuscitation he was pronounced dead.

On necropsy examination there were widespread petechial haemorrhages over the front and sides of the face and neck extending on to the upper part of the trunk. There were pressure marks from the chest of drawers on the lower chest and neck. There was also minor bruising of varying ages in keeping with the "rough and tumble" of childhood. There were no features of deliberate physical abuse. The cardiovascular, gastrointestinal, and genitourinary systems were all normal. The respiratory system was normal apart from mild oedema and congestion of the lungs. There was congestion on the external surface of the brain but no focal abnormality. A skeletal survey showed no bony injury. The findings at necropsy, taken in conjunction with the clinical history, were entirely consistent with death due to traumatic asphyxia.

\section{Discussion}

The syndrome of traumatic asphyxia is an uncommon one and presents with the classical triad of craniofacial cyanosis, petechiae, and subconjunctival haemorrhages. Motor vehicle accidents are the most common cause of traumatic asphyxia in the paediatric population. $^{25-9}$ It is typically associated with transient ischaemic neurological deficit and injuries to the thorax and abdomen. Despite the dramatic appearance of the masque ecchymotic ${ }^{1}$ the outcome is generally good if the patient survives the initial few hours following injury. ${ }^{5-710}$ In 1908 Bolt suggested that there were four principal factors in the pathogenesis of traumatic asphyxia. ${ }^{11}$ These are deep inspiration, closure of the glottis, splinting of the thoracic and abdominal musculature, and thoracic or upper abdominal compression. $\mathrm{He}$ postulated that in order to produce the classical features of traumatic asphyxia there must first be a "fear response" in which the victim, apprehensive of imminent injury, takes and holds a deep breath. This allows the generation of far higher thoracic pressures than compression alone. The pathogenesis of the cutaneous features of traumatic asphyxia has yet to be fully elucidated. Animal studies to date have yet to reproduce all the clinical features associated with the condition. ${ }^{612}$ The most widely accepted explanation is that following a compressive force to the chest or upper abdomen positive pressure is transmitted to the mediastinum, forcing blood out of the right atrium into the innominate and jugular veins. This leads to an increase in pressure in the small venules and capillaries of the face and head, causing petechial haemorrhages. The small vessels become atonic following 
compression and do not regain tone for several days. It is the pooling of desaturated stagnant blood in the atonic vessels that gives the cyanotic facial appearance. It has been recorded that the cyanosis does not occur over points of pressure such as hat bands or collars. This has been ascribed to counter pressure on the skin, preventing venous and capillary distension. In two of the fatal cases described by Williams the patients had no warning before the crushing injury; these patients did not develop the classical craniofacial cyanosis. Lee et al reported a fear response in 12 out of 14 patients in their series. $^{8}$

Large variations in duration and weight of compression have been described. Animal studies $^{612}$ on guinea pigs and dogs show that the incidence of death due to traumatic asphyxia is a function of absolute weight and duration of compression. Weights of up to 7 tons have been tolerated for short periods. ${ }^{13}$ Conversely, substantially lower weights have caused death when the compression was prolonged. Seven of the eight fatal cases presented by Williams ${ }^{6}$ involved prolonged crushing force. In this situation death results from complete restriction of respiratory movement. In the absence of prolonged compression death is due to associated injuries. ${ }^{14}$ The victims of the Hillsborough disaster showed few of the typical signs of traumatic asphyxia, having been exposed to a gradual and prolonged crush rather than a sudden compressive force, thus emphasising the importance of the fear response in generating the traumatic asphyxia syndrome. The term "crush asphyxia" was coined to describe the variation on traumatic asphyxia experienced at Hillsborough. $^{3}$

The two cases we describe illustrate the classical features of traumatic asphyxia uncomplicated by skeletal or thoracoabdominal visceral injury. The child who survived experienced a large crushing force over a very brief period. In comparison the compressing force in the fatal case was fairly modest, but presumably sufficient to prevent all respiratory excursion, leading to hypoxic cardiac arrest. There are several reports of survival following a large crushing weight being applied for a short periods of time. ${ }^{1314}$ Other reports describe survival after periods of entrapment of between two and ten minutes. ${ }^{6}$ Gorenstein et al recorded only two fatalities in their series of 16 cases of traumatic asphyxia in paediatric patients. ${ }^{5}$ Both cases were found to have hypoxic encephalopathy at necropsy; one had severe abdominal injuries in addition. It is not possible to compare outcome in adults and children due to the low number of reported cases; however, fatalities in both groups are related to the weight and duration of compression and associated injuries. The fatal case in our report is notable in that the death occurred in the absence of any other injury. It is all the more tragic in that death is rare in such cases. ${ }^{5}$ This case illustrates the hazards of children being left unsupervised in rooms where inadequately secured large pieces of furniture are present. It is obviously desirable that parents should be informed of such risks.

The treatment of traumatic asphyxia is supportive. Assisted ventilation may be required in cases of chest wall disruption, underlying lung parenchymal damage, or respiratory depression secondary to cerebral hypoxia. Subsequent treatment is directed towards other specific associated injuries.

We wish to thank Mr J D Orr for allowing us to report the details of his patient.

1 D'Angers O. Relation medicale des evenements survenus au Champs de Mars Le 14 Juillet 1837. Ann d'Hyg 1837;18:485-9.

2 Haller JA, Donahoo IS. Traumatic asphyxia in children: pathophysiology and management. J Trauma 1971;2: 453-7.

3 Wardrope J, Ryan F, Clark G, Venables G, Courtney Crosby A, Redgrave P. The Hillsborough tragedy. BMJ 1991;303: A, Redg

4 Channer KS, Edbrooke DL, Moores M, McHugh P, Michael S. Acute right heart strain after crushing injury at Hillsborough Football ground. BMJ 1989;299:1379-80.

5 Gorenstein L, Blair GK, Shandling B. The prognosis of traumatic asphyxia in childhood. J Pediatr Surg 1986;21: 753-6.

6 Williams JS, Minken SL, Adams JT. Traumatic asphyxia reappraised. Ann Surg 1968;167:384-92.

7 Jongewaard WR, Coghill TH, Landercasper J. Neurological consequences of traumatic asphyxia. J Trauma 1992;32: 28-31.

8 Lee MC, Wong SS, Chu JJ, Chang JP, Lin PJ, Shien MJ, et al. Traumatic asphyxia. Ann Thorac Surg 1991;51:86-8.

9 Baldwin GA, McNab AJ, McCormack AQ. Visual loss following traumatic asphyxia in children. J Trauma following traumat

10 Laird WR, Borman MC. Traumatic asphyxia with a report of 5 additional cases. Surg Gynecol Obstet 1930;00:578-

11 Bolt RA. Traumatic asphyxia, report of a case. Cleveland Med J 1908;7:647.

12 Furuya Y. Experimental traumatic asphyxia, grades of thoracic compression and mortality. Igaku Kenkyu 1981; 51:117-9.

13 Parker FJ. Optic atrophy from traumatic asphyxia with report of a case. Ann Ophthalmol 1911;40:159-62.

14 Fred HL, Chandler FW. Traumatic asphyxia. Am J Med 1960;29:508-17.

\section{Accident and Emergency Department, Frimley Park Hospital, Portsmouth Road, Camberley, Surrey GU16 5UJ A Brett \\ T Hodgetts \\ Correspondence to: Dr A Brett.}

Accepted for publication 5 September 1996

\section{Abdominal aortic aneurysm presenting as meralgia paraesthetica}

\author{
Andrew Brett, Tim Hodgetts
}

\author{
Abstract \\ A case of abdominal aortic aneurysm is \\ reported in a patient with long standing \\ low back pain, presenting as meralgia \\ paraesthetica and an increase in the
}

severity of back pain. The case highlights the need for objective assessment of new symptoms arising in a chronic condition, and for a systematic approach to the assessment of radiographs performed in 